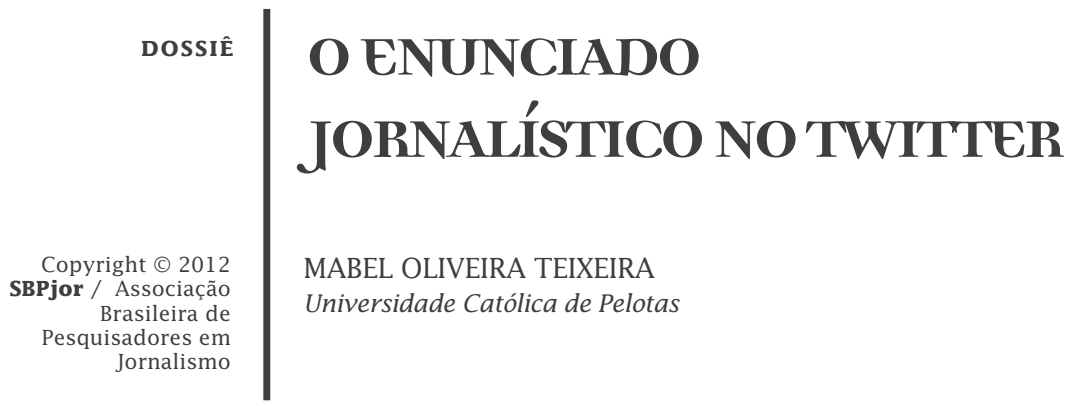

RESUMO - O artigo discorre sobre o impacto das características da plataforma Twitter para a aplicação da técnica jornalística padrão (TRAQUINA, 2008) durante a constituição e produção das notícias veiculadas como tweets; e, ao mesmo tempo, busca apontar suas especificidades em relação ao enunciado jornalístico tradicional. A partir da análise de 134 tweets, coletados dos perfis do jornal Folha de S. Paulo, Zero Hora e Diário Popular, obtivemos indícios que nos levaram a confirmar nosso pressuposto central, ou seja, que o padrão hierárquico e objetivo que orienta a constituição da notícia padrão e, portanto, da própria linguagem que caracteriza o jornalismo tradicional, começa a ceder espaço a modelos mais horizontalizados e interativos que remodelam a técnica padrão (baseada no modelo da Pirâmide Invertida) e, consequentemente, modificam o enunciado jornalístico - interferindo em seus efeitos discursivos (GOMES, 2000).

Palavras-chave: Linguagem jornalística. Enunciado jornalístico. Tweets jornalísticos. Twitter.

\title{
THE JOURNALISTIC UTTERANCE ON TWITTER
}

ABSTRACT - This article aims to discuss the impact of the characteristics of the Twitter platform on the application of standard journalistic technique (TRAQUINA, 2008) during the creation and production of news releases as tweets and, at the same time, it seeks to identify their specifications regarding traditional journalistic utterances. Through the analysis of 134 tweets collected from newspaper profiles of Folha de S. Paulo, Zero Hora and Diário Popular, we have obtained indications that led us to confirm our central assumption. In other words, the hierarchical pattern and purpose that guide the creation of standard news, and therefore, the special language that characterizes traditional journalism, begin to give way to models that are more horizontal and interactive, that redesign the standard technique (based on the model of the Inverted Pyramid) and thus, modify journalistic writing - interfering in its discursive effects (GOMES, 2000).

Keywords: Journalistic language. Journalistic utterances. Journalistic tweets. Twitter. 


\section{INTRODUÇÃO}

O uso dos computadores e, especialmente, da Web estimulou alterações técnicas, morfológicas e culturais, causando profundas mudanças na forma de produzir e reproduzir textos, nos suportes da escrita e nas atividades comunicacionais. Com a popularização da Web, o homem tornou-se usuário e criador de novas ferramentas de comunicação, assumiu-se frente à tecnologia e, concomitantemente, passou a ter todos os aspectos de sua existência afetados por ela. Quando, portanto, falamos em novos aparatos tecnológicos estamos, simultaneamente, discutindo todos os processos sociais, econômicos, históricos e culturais que estão simbioticamente relacionados com a evolução técnica.

Dito isso, localizamos o objeto de nosso estudo, os enunciados jornalísticos no Twitter, como filhos legítimos desse novo momento histórico marcado pelo papel central das trocas de informação, organização social em redes cibernéticas e horizontalização dos processos comunicacionais. O Twitter, apropriado como plataforma de mídia e site de rede social (SRS), é um sistema que colabora com a potencialização das características conectivas, abrangentes, mais igualitárias e democráticas, que postularam a Web como o marco definitivo da chamada era informacional (CASTELLS, 2010).

De forma sucinta podemos dizer que o Twitter é um site de microblogging que pode ser utilizado para diversos fins, como: interagir com outros usuários, publicar e receber notícias, replicar e discutir conteúdos divulgados na plataforma etc. Desde seu lançamento em 2006, o Twitter ganhou enorme popularidade pela simplicidade de sua interface e pela eficácia de suas ferramentas para a exploração das características mais marcantes da Web e da sociedade em rede: instantaneidade, interatividade, personalização, hipertextualidade, mobilidade e convergência (MIELNICZUK, 2002).

Centrado na simplicidade e na facilidade de manuseio, o Twitter funciona através da publicação de conteúdos (denominados tweets) que devem sempre ficar restritos a 140 caracteres e se propõem a responder a seguinte questão: O que está acontecendo?' Para responder a esse questionamento, os usuários (twitteiros) podem enviar seus tweets através da Web, Internet móvel, e-mail, etc. Cabe destacarmos que a característica mais relevante do Twitter é que ele permite que as informações sejam produzidas por todos e para todos através de um fluxo contínuo de trocas, interações e hiperconexão de conteúdos.

Para buscarmos caracterizar o enunciado jornalístico no Twitter nos apoiaremos em uma tríade de elementos: o modelo técnico padrão 
de constituição da notícia (enunciado jornalístico padrão), a linguagem jornalística padrão e as novas possibilidades advindas com a ferramenta Twitter. Pretendemos atingir nosso objetivo respondendo a seguinte questão: de que maneira as características da plataforma Twitter incidem sobre a aplicação da técnica jornalística padrão na constituição e produção das notícias veiculadas como tweets e quais são suas possíveis especificidades em relação ao enunciado jornalístico tradicional? Nossa hipótese central é a de que o padrão hierárquico e objetivo que orienta a constituição da notícia padrão e, portanto, da própria linguagem do jornalismo que (re)conhecemos, começa a ceder espaço a modelos mais horizontalizados e interativos que remodelam a técnica padrão (baseada no modelo da Pirâmide Invertida) e, consequentemente, modificam o enunciado jornalístico.

Para responder ao questionamento supracitado, nos apoiaremos na análise dos 134 tweets noticiosos que irão compor a materialidade de nosso corpus. O material para a análise foi coletado, ao longo do dia 16 de junho de 2011 , dos perfis no Twitter dos jornais Folha de S. Paulo, Zero Hora e Diário Popular, conforme será exposto em nossa metodologia. Nossa motivação para a elaboração do presente estudo está, sobretudo, vinculada a uma inquietação pessoal sobre os efeitos das novas ferramentas de comunicação na constituição das notícias e, ao mesmo tempo, ao interesse acadêmico de explorar um fenômeno que está em andamento e cujos trabalhos científicos ainda são escassos.

\section{O enunciado jornalístico padrão}

Trabalhando com a noção de "campo do saber", Traquina (2005) define o jornalismo como uma realidade seletiva construída através de inúmeros processos de interação social entre os profissionais do campo jornalístico e as fontes, os outros jornalistas e a própria sociedade na qual está inserido. Essa "realidade seletiva" apontada por Traquina é, em última análise, a própria conformação da notícia que, antes de ser a expressão da realidade, é o produto resultante das interações sociais.

O jornalismo é, portanto, uma atividade representada pelo seu principal produto, a notícia - uma construção social da qual os jornalistas se apropriam como um saber específico, materializado por meio de procedimentos especializados de narração, em especial, o modelo da Pirâmide Invertida $(\mathrm{PI})^{2}$. Podemos dizer assim, que por meio das técnicas de narração adotadas para a constituição da notícia, o jornalismo se coloca através de uma linguagem própria, ou, como prefere Traquina, (2008) o “jornalês", que produz e garante estabilidade aos seus enunciados 3 .

Para entendermos tal linguagem necessitamos, portanto, 
observar os elementos que constituem a estrutura da PI (FRANCO, 2001), a saber: a) o Lide, primeiro parágrafo da notícia que visa abarcar as principais informações de um fato ("o quê?", "quem?", "quando?", "onde?", "como?" e "por quê?"); b) o sublide (que pode ser composto pelo "como?" e pelo "por quê?" ou por uma maior exploração desses); c) parágrafos de contextualização; e d) os materiais secundários ou irrelevantes ao entendimento do relato. Explorando o conceito de Lide, Sousa destaca que este "é, em primeiro lugar, o parágrafo que introduz o tema da peça e, em segundo lugar, o parágrafo que dá o tom ao resto da peça"; e sendo assim, destaca que "então a estrutura que decidiu adoptarse (sic) para peça condiciona o lead" (FRANCO, 2001, p. 221, grifo do autor).

A técnica jornalística padrão estipula aos jornalistas certas regras estabilizadas (mas não imutáveis) de organização textual de seus enunciados. A intervenção imposta aos produtos da fala jornalística é, antes de tudo, um mecanismo que consolida uma linguagem própria à atividade. Nas palavras de Traquina,

\begin{abstract}
a linguagem jornalística deve possuir certos traços que vão no sentido de ser compreensível: a) frases curtas; b) parágrafos curtos; c) palavras simples (evitar palavras polissilábicas); d) uma sintaxe direta e econômica; e) concisão; e f) a utilização de metáforas para incrementar a compreensão do texto [...]. O jornalês é geralmente forçado a um formato específico na imprensa: a pirâmide invertida, que se tornou dominante no jornalismo norte-americano por volta de 1900 (TRAQUINA, 2008, p. 46).
\end{abstract}

A linguagem jornalística padrão é, assim, uma construção discursiva atravessada pelos valores, ideologias e marcas históricas de uma sociedade fundamentalmente tipográfica, industrial e positivista - a sociedade do século XIX - que consolidou o modelo ocidental das notícias, ou seja, a PI. Esse "modo de dizer" do jornalismo substancialmente ligado ao seu "saber de narração"4 (TRAQUINA, 2008) é reflexo de uma fala característica da cultura moderna que buscava e valorizava as mensagens universais e a fixação de sentidos considerados imanentes (LÉVY, 1999).

Sendo assim, trazemos o jornalismo para o cerne de nossa discussão apontando que, em sentido amplo, a notícia é sinônimo de "enunciado jornalístico" (CORREIA, 2011), entendida como o produto do ato da enunciação ${ }^{5}$. Ora, se o enunciado é o resultado "observável" da ação do sujeito falante, então, estando o jornalismo incumbido do processo accional de noticiar, torna-se lógico que o enunciado primário do jornalismo será sempre a notícia. A nós interessam, particularmente, as características específicas que o enunciado jornalístico assume ao adotar um sistema técnico próprio que busca estabilizar a forma dos enunciados 
em interação com o corpo social. Utilizamos os apontamentos feitos por Mayra Gomes (2000), ao tratar da enunciação jornalística através das ciências da linguagem, para propormos tais características. O resultado encontrado pela autora nos levou a definir o enunciado jornalístico padrão como: a) impessoal, b) hierarquizado, c) conciso, d) assertivo/ constatativo, e) objetivo, e f) excludente.

Destacamos que todas as caracterizações apontadas são alcançadas por meio de estratégias técnicas de redação que são acionadas no momento da enunciação jornalística. Seus efeitos, portanto, são configurados através do sistema simbólico da língua que, quando posto em ação, gera sentidos específicos em um dado contexto. Assim, todas as características dos enunciados jornalísticos são reflexos de uma técnica que visa, em última análise, transformar a notícia em um relato objetivo que possa atingir o efeito de realidade desejado. Dessa forma, a atividade jornalística é posta através de um conjunto de práticas e técnicas que visam à estabilidade dos enunciados noticiosos, criados e consumidos como produtos, que funcionam como organizadores do espaço social e mediadores do caos informativo legitimando-se através do discurso referencial ${ }^{6}$.

\section{O twitter e seus elementos técnicos}

Pesquisadores como Castells (2010), Lévy (1999), Santaella e Lemos (2010), Recuero (2009) e Zago (2008) apontam, cada um sob determinado foco, para a constituição de uma nova sociedade que se "realiza" e "institui" em processos comunicacionais inovadores que criam linguagens híbridas constantemente atualizadas pela interação em rede. Esses fenômenos sociais e, portanto, linguísticos estabelecem um novo contexto aos enunciados jornalísticos, um novo universo simbólico pelo qual passam a produzir novas significações e valores. Através das diversas ferramentas de colaboração e de interatividade disponíveis na Web, os usuários se habituaram a produzir e partilhar seus conteúdos e, ao mesmo tempo, colaborar com o conteúdo criado por outros. Sites como o Twitter são reflexo direto dessa fase de interação permanente e da intensa democratização dos espaços para a veiculação dos mais variados discursos ${ }^{7}$ e para a representação dos mais diversos sujeitos.

Desde seu aparecimento o Twitter teve, pelo menos, dois grandes modos de usos e apropriações: se tornou, ao mesmo tempo, uma popular ferramenta de conversação e de informação. O crescente número de veículos de comunicação e de jornalistas profissionais que adotaram o Twitter como uma poderosa ferramenta noticiosa é, certamente, uma forte refutação à ideia de que a Web e suas ferramentas marcariam o fim 
do jornalismo profissional. Todavia, a maneira de informar ganha novas características e possibilidades já que o Twitter é, em sua essência, um site de rede social ${ }^{8}$ (SRS). Assim, o valor das informações que circulam pelo Twitter não está apenas vinculado com sua origem, mas também ao debate que suscita (ZAGO, 2008).

As características da prática jornalística no Twitter são, em boa parte, reflexo das próprias especificidades da ferramenta que, segundo Zago (2008), podem ser resumidas através da: atualização por dispositivos móveis; limitação de 140 caracteres por mensagens; atualização automática; e configuração como um site de rede social SRS. Sendo assim, com base nas ideias da autora, observamos que as especificidades da ferramenta incitam que seus conteúdos possuam características de: instantaneidade; hiperconcisão; agilidade/velocidade extrema; interação/conversação.

Salientamos que a efetivação de tais características depende não apenas das possibilidades do sistema, mas também da apropriação à qual está submetida. Podemos dizer, resumidamente, que o Twitter possui um sistema linguístico próprio do qual os twitteiros fazem uso para produzir suas mensagens e sentidos. Como elementos básicos da linguagem da ferramenta temos: o link, um método simples de passar de um ponto do documento para outro ponto interno ou externo; o retweet (RT), mecanismo utilizado para indicar que o conteúdo que está sendo publicado é proveniente de outro usuário; a hashtag (\#) que pode ser entendida como indexador de temas, tópicos e/ou palavras-chave que reúnem conteúdos relacionados; a arroba (@) cuja definição é dada por Ramos (2010, p. 38) como "sinônimo de gente [...] tem força magnética na linguagem, principalmente em sua sintaxe", em suma, a arroba é o símbolo que precede o TwitterNome, a identificação de cada usuário no sistema.

As últimas três funcionalidades supracitadas (RT, \# e @) caracterizam um novo sistema de microssintaxe específico do Twitter. Esse sistema é reflexo da restrição de 140 caracteres e é exemplo da fluência mínima em microssintaxe, que é requisito básico para a navegação e inserção bem-sucedida na ferramenta (LEMOS; SANTAELLA, 2010). A presença desses elementos de codificação é tão arraigada ao próprio funcionamento do Twitter que sua não observância impossibilita a comunicação e a troca. Sendo o jornalismo uma atividade voltada à transmissão de mensagens, não haveria outra forma de explorar o potencial midiático da ferramenta Twitter senão através da apropriação de sua sintaxe, de sua linguagem e organização. Dessa forma, os jornalistas entraram em um processo de assimilação e de apropriação 
dos novos signos, adaptando e explorando as novas possibilidades à sua atividade. Cabe, portanto, explorarmos quais os efeitos desse processo nos enunciados jornalísticos produzidos.

\section{Metodologia}

Para nossa pesquisa, delimitamos como objetos potenciais apenas os conteúdos publicados por empresas jornalísticas que adotaram o Twitter como ferramenta de comunicação. Nosso objeto de estudo se constitui, portanto, de "tweets jornalísticos", ou seja, os produtos veiculados por empresas jornalísticas em seus perfis no Twitter. Para nos aproximarmos da heterogeneidade de jornais que criaram seus espaços na Web, optamos por sujeitos que não pertencessem ao mesmo grupo empresarial e, ao mesmo tempo, que não possuíssem a mesma área de cobertura.

Sendo assim, decidimos nos debruçar sobre os tweets publicados por: a) um veículo de expressão nacional, a Folha de S. Paulo (FSP); b) outro de especial destaque no Rio Grande do Sul (RS), a Zero Hora (ZH); c) um representante do jornalismo realizado na região sul do RS, o Diário Popular (DP). Para limitarmos o número de tweets que constituiriam nosso corpus e, ao mesmo tempo, evitarmos critérios que pudessem favorecer uma seleção baseada na qualidade ou na riqueza de dados dos tweets, restringimos como critério de seleção dos tweets o próprio período de coleta do material: o dia 16 de junho de 2011 . Os tweets publicados pelos veículos selecionados foram coletados manualmente em todos os perfis. Ao final de nossa coleta, alcançamos um total de 134 tweets.

Com o corpus delimitado, buscamos aplicar, gradualmente, algumas sistematizações que auxiliassem a compreensão de suas características mais relevantes. Nossa primeira medida consistiu em identificar os sujeitos, quantificar o número de tweets publicados por cada um e, concomitantemente, identificar as respectivas utilizações que fizeram das principais funcionalidades técnicas oferecidas pelo Twitter. O resultado obtido por meio desse primeiro olhar pode ser apreciado no Quadro 1:

Quadro 1 - Dados coletados dos perfis selecionados

\begin{tabular}{|l|c|c|c|c|}
\hline & Folha de S. Paulo & Zero Hora & Diário Popular & Total \\
\hline Identificação & @folha_com & @zerohora & @diariopopularRS & -- \\
\hline Seguidores & 118.280 & 93.589 & 6.873 & 218.742 \\
\hline $\mathbf{N}^{\mathbf{0}}$ de usuários seguidos & 66.934 & 9.810 & 64 & 76.808 \\
\hline Tweets coletados & 52 & 35 & 47 & 134 \\
\hline Uso de links & 50 & 32 & 40 & 122 \\
\hline Uso de @ & 12 & 04 & -- & 16 \\
\hline Hashtags & -- & -- & 05 & 05 \\
\hline Retweets & 08 & 02 & -- & 10 \\
\hline
\end{tabular}

Fonte: elaboração da autora 
O Quadro 1 demonstra que as possibilidades técnicas da plataforma Twitter, especialmente, o link, o retweets, a hashtag e a arroba, estão sendo efetivamente apropriadas para a constituição dos "tweets jornalísticos". A utilização dos elementos da microssintaxe do Twitter caracteriza o hibridismo que permeia os "tweets jornalísticos", ou seja, ao mesmo tempo em que encontramos a presença de elementos da técnica padrão do texto jornalístico, encontramos também a inserção dos elementos de microssintaxe oriundos do Twitter. A soma desses elementos dá origem a uma linguagem nova, diferenciada e específica, que se faz ver através dos novos enunciados produzidos.

\section{Análise: o enunciado jornalístico no Twitter}

A partir da análise dos "tweets jornalísticos", iremos salientar algumas das diferenças entre eles e os enunciados tradicionais. Simultaneamente, apontaremos alguns efeitos e motivações para o aparecimento dessas singularidades e suas marcas materiais nos enunciados analisados. Para resumirmos e visualizarmos algumas dessas marcas, sugerimos a apreciação do Quadro 2:

Quadro 2 - Descaracterização do enunciado padrão

\begin{tabular}{|c|c|}
\hline $\begin{array}{l}\text { Características do enunciado } \\
\text { jornalístico padrão }\end{array}$ & Principais marcas de descaracterizações \\
\hline Impessoalidade & $\begin{array}{l}\text { Pontos de exclamação, interação com usuários e presença } \\
\text { de emoticons. }\end{array}$ \\
\hline Hierarquização por relevância (PI) & $\begin{array}{l}\text { As informações não são organizadas em função de sua } \\
\text { relevância, presença do link e aparição do "microlide". }\end{array}$ \\
\hline Assertivo/constatativo & Intervenção dos usuários nos conteúdos publicados. \\
\hline Objetivo & $\begin{array}{l}\text { Pontos de exclamação, interação com usuários, presença } \\
\text { de emoticons. }\end{array}$ \\
\hline Conciso & Microlide e 140 caracteres. \\
\hline Excludente & $\begin{array}{l}\text { Interação com usuários, intervenção dos usuários, } \\
\text { presença de emoticons e uso de pontos de exclamação. }\end{array}$ \\
\hline
\end{tabular}

Fonte: elaboração da autora

No referido Quadro 2, podemos observar, na coluna direita, a exposição das já mencionadas características do enunciado jornalístico padrão; já na coluna esquerda observamos alguns dos indícios textuais e linguísticos que marcam a descaracterização ou reformulação do enunciado padrão quando apresentado no formato de tweet. Buscando maior dinamismo, apresentaremos na sequência cada uma das características do enunciado padrão e, simultaneamente, os apontamentos sobre suas alterações ou inaplicabilidade nos tweets. 
Ao falar sobre a impessoalidade do enunciado jornalístico padrão, Gomes (2000) destaca que ela se efetiva através da estratégia de se contar os fatos de um terceiro por meio do verbo na terceira pessoa (ele/eles). Ao adotar tal estratégica linguística, a notícia discorre como se não houvesse nenhuma colocação de valores ou mediação permeando seu enunciado. Nos tweets jornalísticos, entretanto, a impessoalidade do enunciado padrão começa a ser negligenciada em função do caráter explicitamente dialógico do Twitter. Esse fenômeno é explicitado pela presença de elementos incomuns à linguagem jornalística padrão, como vemos nos tweets abaixo:

Quadro 3 - Tweets com marcas dialógicas

\begin{tabular}{|c|c|}
\hline FOLHA & $\begin{array}{l}\text { folha_com Folha de S.Paulo } \\
\text { @kevinschwaantz De nada! =) } \\
23 \text { hours ago }\end{array}$ \\
\hline$\underline{Z}$ & $\begin{array}{l}\text { zerohora Zero Hora } \\
@ \text { riicardo_souza Ricardo, corrigimos o texto. Obrigado } \\
30 \text { minutes ago }\end{array}$ \\
\hline
\end{tabular}

Fonte: elaboração da autora

Nos tweets observados, percebemos o estabelecimento expresso de diálogos. Nesses enunciados, a linguagem jornalística cede espaço à linguagem interativa do meio, há referências diretas a enunciatários determinados que estão inseridos e expressos no dizer jornalístico. Mais que isso, o último tweet exposto expressa um caráter não apenas interativo, mas também colaborativo entre a $Z \mathrm{ZH}$ e o usuário Ricardo_Souza. Outra interessante observação pode ser visualizada no primeiro tweet, onde há a indicação material do gênero do sujeito falante através do uso do adjetivo "obrigado" e a representação tipográfica deste através da inserção de um emoticon que expressa satisfação e a informalidade da fala.

Os conteúdos do tweets apresentados não possuem nenhum caráter informativo ou noticioso, mas dividem o mesmo espaço no fluxo informacional. Podemos apontar, portanto, que a característica interativa e dialógica do Twitter potencialmente atua na construção dos enunciados jornalísticos. A igualdade de espaços entre os usuários coage o jornalismo a se corrigir publicamente e em tempo real; os enunciados aparentemente inabaláveis e indiscutíveis do jornalismo tornam-se mais frágeis em função da interação mais democrática e instantânea suscitada pela ferramenta.

A característica de hierarquização das informações imposta pela $\mathrm{PI}$ ao enunciado padrão remete-nos à urgência do relato jornalístico 
e a sua busca pela objetivação dos acontecimentos que se impõem como atuais. No Twitter, a hierarquização da PI dá lugar a uma estrutura que obedece à lógica da hiperconcisão, da hipertextualidade, da personalização, da agilidade extrema e da interconexão potencialmente infinita de conteúdos. Essa dinâmica hipertextual da estrutura está vinculada ao aspecto informacional da rede pelo qual uma informação precisa ser, ao mesmo tempo, elementar (ágil, essencial e hiperconcisa) e interativa (permitindo sua exploração exponencial).

Ao observarmos os primeiros dados que destacamos na apresentação do corpus, ficou nítida a ampla utilização de links na constituição dos tweets. Destacamos que os conteúdos desses tweets apareceram, muitas vezes, como links de notícias externas que estavam, por sua vez, ligadas a outras células informativas e assim sucessivamente. Fazendo um paralelo com o texto jornalístico padrão, poderíamos dizer que cada uma das células corresponde a um parágrafo do texto impresso. Entretanto, ao contrário dos parágrafos da notícia impressa que são hierarquizados em função da relevância informativa de seus conteúdos (PI), as células informativas que encontramos através de nosso corpus não seguem essa lógica. O exemplo abaixo demonstra que entre o tweet (à esquerda), considerado a Célula 1, e o Lide (à direita) da notícia linkada, considerado a Célula 2, não há uma hierarquização baseada na importância dos dados entre as células, mas que a diferença entre elas está baseada na quantidade de informações dispostas:

Quadro 4 - Exploração gradual de informações

\begin{tabular}{|c|c|c|}
\hline $\mathrm{f}_{\text {Fо대 }}$ & $\begin{array}{l}\text { folha_com Folha de S.Paulo } \\
\text { Por unanimidade, Supremo libera Marcha da Maconha. } \\
\text { http:I/bit.ly/lxg2EP (via @folha_cotidiano) } \\
20 \text { hours ago }\end{array}$ & $\begin{array}{l}\text { O STF (Supremo Tribunal Federal) liberou nesta quarta-feira } \\
\text { a realização da Marcha da Maconha, evento que reúne, em } \\
\text { diversas cidades brasileiras, pessoas favoráveis à legalização } \\
\text { da droga. }\end{array}$ \\
\hline & (-) informações & \\
\hline
\end{tabular}

Fonte: elaboração da autora

Com base nessa observação que se confirmou em todos os tweets com links, nos pareceu evidente que a construção noticiosa que observávamos não remetia ao tradicional modelo da $\mathrm{PI}$, mas, sim, ao modelo da Pirâmide Deitada (PD) proposto por Canavilhas (2006). De acordo com o autor, quando inseridos no ambiente hipertextual da Web, as células informativas que compõem o relato noticioso passam, geralmente, a obedecer a uma lógica diferente daquela aplicada à notícia padrão onde cada célula, no caso os parágrafos, visam estabelecer uma hierarquização decrescente baseada na importância dos dados apresentados.

Em suma, Canavilhas (2006) nos coloca que a exploração 
jornalística do fato passa a não mais obedecer ao critério de relevância da PI, mas sim a uma exploração que vai, gradualmente, acrescentando, através de novas células ${ }^{9}$, uma maior quantidade de detalhes com relação aos elementos apresentados. Ao observamos o exemplo dado no Quadro 4, percebemos que a informação do tweet (a liberação da marcha da maconha) é acrescida de uma maior exploração dos detalhes no Lide da notícia linkada, mas essa não apresenta nenhuma diferença hierárquica com relação ao tweet, uma vez que permanece centrada no fato central: a liberação da marcha da maconha. Sendo assim, podemos dizer que entre as Células 1 e 2 não há diferenciação hierárquica entre os dados expostos. Nosso olhar sobre o corpus, portanto, corroborou o esquema proposto por Canavilhas (2006), uma vez que os tweets analisados funcionavam, dentro do macrocontexto da notícia on-line (com suas múltiplas células hiperconectadas), como uma unidade informativa inicial de onde o leitor poderia partir rumo a uma exploração que, gradativamente, ampliava a abordagem de cada um dos elementos apresentados no tweet. Dentro dessa perspectiva horizontalizada, o tweet acaba se formatando como uma espécie de unidade-base que introduz o acontecimento noticioso, o qual vai sendo acrescido de detalhes a cada novo link, a cada nível da PD.

Toda a aplicação da técnica da PI, em destaque do Lide, serve a este efeito de um dizer enxuto, desprovido de complexidade, que visa captar o fato em essência. Se a notícia padrão é considerada como um enunciado conciso (frases curtas, sintaxe direta, lide), o tweet jornalístico (única frase em 140 caracteres, microssintaxe) pode ser considerado como o extremismo dessa característica, simbolizada pela criação do "microlide". Dos 134 tweets que constituem nosso corpus, 91\% (122 tweets) estão voltados à apresentação de dados importantes para a compreensão de um acontecimento factual, ou seja, focam-se em noticiar algo. Detivemo-nos nesses exemplares para buscar identificar a presença dos elementos que compõem o Lide. $\mathrm{O}$ resultado foi: 122 tweets atenderam à questão "o quê?"; 99 atenderam à questão "quem?"; 14 à questão “quando?"; 45 à questão "onde?"; 13 à questão "como?"; e 10 à questão "por quê". De acordo com o observado, nos parece evidente que os tweets analisados não poderiam ter sido originados pela mera transposição do Lide, uma vez que alguns de seus elementos parecem ser negligenciados sistematicamente. Parece óbvio que com a limitação, imposta pelo Twitter, de um texto de no máximo 140 caracteres, a veiculação integral do Lide seria uma tarefa quase impossível. Apesar disso, Zago (2008) nos indica que os jornalistas não apenas passaram a utilizar o Twitter, como também o tornaram 
um dos meios mais eficientes de noticiar. Isso foi possível graças a um fenômeno que optamos por chamar de "microlide", ou seja, um novo núcleo informativo essencial ainda mais conciso - "hiperconciso" - que o Lide tradicional, que se concentra em atender apenas as seguintes questões: "o quê?", "quem?" e "onde?".

Ao colocarmos o enunciado padrão como assertivo/constatativo recorremos, mais uma vez, a Gomes (2000) quando, ao tratar da enunciação jornalística, aproxima o discurso jornalístico do discurso histórico em função de ambos tratarem os fatos relatados como se estivessem ligados linguisticamente a um privilégio de ser: conta-se o que passou, não o que ainda não aconteceu ou é duvidoso. No Twitter, tal ideia parece estar à mercê do contexto interativo e polissêmico da plataforma que impõe um caráter de incompletude imanente, um aspecto de "versão" sempre aberta às significações e verificações dos usuários. Nesse ambiente simbólico, as "verdades" são sempre consideradas múltiplas e provisórias. Dessa maneira, as estratégias da linguagem padrão tornam-se limitadas e insuficientes para anular os efeitos gerados pela linguagem do sistema. Assim, embora a maior parte dos tweets analisados mantenha uma linguagem que busca a tradicional objetividade do fato relatado através de uma construção impessoal e constatativa, a interação com outros usuários, a presença de certos sinais gráficos (!) e o uso de links ${ }^{10}$ interferem, de certa forma, na articulação simbólica que visa gerar a ilusão referencial através de uma linguagem que busca escamotear os signos dos sujeitos da enunciação.

A utilização de sinais gráficos que exprimem emoção e/ ou ênfase contraria a técnica jornalística padrão - o uso desse tipo de pontuação só costuma ser aceito quando inserido em citações ou em casos muito específicos. O uso do ponto de exclamação marca a presença do sujeito enunciador - isso significa que sua ocorrência em enunciados jornalísticos (notícias) é uma das novidades que marcam uma linguagem muito específica do jornalismo dentro do Twitter, onde a impessoalidade e a objetividade da linguagem tradicional, características antes inegociáveis no jornalismo, começam a ceder espaço a uma linguagem menos burocrática e mais interativa.

O jogo de referencialidade do dizer é o pressuposto central da objetividade da notícia padrão, ou seja, se procura um enunciado que não apresente os signos do enunciador para efetivar uma sensação de imparcialidade, objetividade e verdade. Todavia, o caráter conversacional da plataforma Twitter interfere nesse jogo uma vez que impõe a interação entre enunciados e sujeitos que se encontram e se confrontam 
no mesmo fluxo informacional. Ademais, a notícia no Twitter nunca é dada como um relato completo; a própria lógica do ciberespaço suscita a multiplicidade e a incapacidade de apreensão do todo, seja pelo excesso de informação disponível ou pela diversidade de enunciados conflitantes ou, ainda, pelos inúmeros caminhos que podem ser seguidos - é o que Lévy (1999) chama de universal não totalizante característico dos conteúdos produzidos na Rede.

Assim, a característica de exclusão dos signos do leitor e do veículo/jornalista, observada na linguagem padrão, também passa a sofrer interferências quanto à sua aplicabilidade em função da interatividade que a linguagem da rede supõe. Se no enunciado padrão há a permanente exclusão das marcas do enunciador e do enunciatário para sublinhar a característica de objetividade das notícias - eliminando a relação conversacional - no Twitter, essa estratégia linguística confronta os princípios básicos do próprio ambiente e, assim, acaba sendo abandonada em algum momento em nome da interação. Observamos no corpus a presença, ainda que por vezes velada e discreta, dos sujeitos do processo enunciativo (através do uso de emoticons, pontuação gráfica, conversação com leitores etc.). Esses são indícios de uma mudança da prática jornalística que está passando, ao invés de negligenciar, a interagir com seus "leitores" e aceitar suas contribuições na produção/reprodução/ edição dos seus textos - como vimos através dos tweets expostos no Quadro 3. Essa mudança parece se ligar ao caráter interativo, informal e dialógico do próprio ambiente; essa nova prática é potencialmente significativa, uma vez que pode gerar, entre outras coisas, mudanças substanciais na relação dos veículos/jornalistas com suas fontes.

O Twitter transforma cada usuário em um colaborador e em uma fonte virtual de informações variadas, facilmente acessíveis e hiperconcisas; todas essas dinamicidade e heterogeneidade agem em prol da exploração jornalística desse universo interminável de novas "fontes" e colaboradores potenciais. Em suma, acreditamos que a notícia enquanto tweet passa a habitar um novo universo simbólico, completamente reconstruído e ressignificado por meio dessa nova linguagem que emerge do fluxo informacional colaborativo e hipertextual que não nega a mediação, mas a assume como única forma de existência. Desse modo, os enunciados jornalísticos no Twitter passam a apresentar singularidades com relação ao enunciado padrão em função das características que o permeiam, ou seja: a hipertextualidade, a hiperconcisão, a interatividade, a universalidade e a colaboração. 


\section{Conclusões}

Ao iniciarmos este trabalho, nos propomos a investigar e atender à seguinte questão: como as características da plataforma Twitter incidem sobre a aplicação da técnica jornalística padrão nas notícias veiculadas como tweets e quais suas possíveis especificidades em relação ao enunciado jornalístico tradicional? Para chegarmos a uma consideração satisfatória, indicamos que nos guiaríamos através da exploração de uma tríade de elementos que permeiam nosso problema, sendo eles: o modelo técnico padrão de constituição da notícia, a linguagem jornalística padrão, e as possibilidades e características da ferramenta Twitter. Sendo assim, faremos aqui uma síntese dos planos explorados e, simultaneamente, iremos apresentar as considerações que encerram nossa pesquisa.

Vimos, no início deste artigo, que a noção de jornalismo enquanto atividade especializada firma-se e conecta-se com a estabilização de um saber próprio: o que é a notícia e como ela é produzida (TRAQUINA, 2008). Destacamos, que este produto jornalístico é, antes de tudo, um constructo social que fora estabilizado dentro de um contexto sóciohistórico específico, o contexto da sociedade da escrita (LÉVY, 1999), através de procedimentos que originaram uma linguagem própria ao jornalismo, o "jornalês" (TRAQUINA, 2008), e uma estrutura técnica de narração, a Pirâmide Invertida (PI) e, concomitantemente, o Lide. Sendo assim, nosso referencial teórico apresentou a notícia como o enunciado padrão da fala jornalística cuja técnica (incluindo sua linguagem e formato) é posta como estratégia promotora de uma fala idealizada pelo valor de objetividade. Vimos que o contexto pelo qual o jornalismo e seus procedimentos se firmaram terminou por influenciar o reconhecimento do enunciado jornalístico padrão através de características típicas do discurso referencial (GOMES, 2000), ou seja: a impessoalidade, hierarquização, assertividade, constatividade, objetividade e exclusão.

Após termos apresentado o modelo técnico padrão de constituição da notícia e a linguagem jornalística padrão (caracterizando seus enunciados), nos focamos em apresentar o Twitter como um espaço midiático e, ao mesmo tempo, um SRS. Salientamos que algumas possibilidades técnicas da ferramenta - como a limitação de 140 caracteres por mensagem, a atualização (manual ou automática) através de dispositivos móveis e, especialmente, sua configuração como SRS (ZAGO, 2008) - estimulam e influenciam a produção de enunciados caracterizados por sua: hiperconcisão (possibilitada pelos elementos de microssintaxe), hipertextualidade (característica própria das ferramentas 
da Web), agilidade e velocidade (potencializadas pela atualização automática e uso de dispositivos móveis para a publicação) e, por fim, interação/conversação (a característica dialógica é típica e fundamental tanto para a manutenção do SRS como para garantir a visibilidade e a relevância dos usuários).

Ao entrarmos em contato com a materialidade do corpus, pudemos perceber que os tweets jornalísticos apresentam elementos textuais oriundos tanto da linguagem jornalística padrão como da linguagem que emerge do Twitter. Através da análise, no entanto, percebemos que, apesar dos tweets jornalísticos recorrerem a estratégias linguísticas típicas da técnica padrão, sua mera inserção no ambiente da Web e apropriação dos elementos da linguagem do Twitter interferem e, por vezes, limitam os efeitos característicos da fala jornalística padrão (como foi demonstrado, resumidamente, no Quadro 3). Com base na análise do corpus, portanto, nossa primeira consideração é a de que as características e elementos linguísticos do Twitter interferem nos efeitos da linguagem jornalística padrão.

No Twitter, a interação e a colaboração com os demais usuários e conteúdos é condição básica para a definição do grau de visibilidade, influência e credibilidade que o veículo/jornalista assumirá na estrutura do sistema (ZACO, 2008). Assim, acreditamos que o Twitter impõe que a linguagem jornalística passe a admitir o caráter dialógico de seus enunciados e, ao mesmo tempo, certo nível de informalidade e permeabilidade em seus dizeres para garantir sua relevância dentro da Rede. Esse fato pôde ser observado por meio da materialidade de tweets conversacionais trocados entre twitteiros e veículos/jornalísticos. Em suma, cremos que o processo de significação dos novos enunciados jornalísticos não está mais baseado na pressuposição de uma autossuficiência enunciativa capaz de negar qualquer interferência entre o fato e o relato, mas sim na interconexão, interação e colaboração necessárias à participação do diálogo explícito do Twitter.

Durante nossa análise, pudemos observar as mudanças que aparecem na própria textualidade dos enunciados por meio de elementos que caracterizam a interação, a hipertextualidade, o diálogo e até mesmo a interferência do enunciador e dos enunciatários na produção dos tweets. Vimos que, por estarem inseridos no ambiente hipertextual da Web, o tweet jornalístico passa a integrar uma (macro) estrutura não linear de exploração da informação na qual assume o papel de "unidade-base" de onde se pode partir rumo a um maior detalhamento dos dados apresentados através da exploração de outras 
células informativas previamente linkadas. Sendo assim, o enunciado jornalístico no Twitter parece já não estar ligado à arquitetura hierárquica da PI, mas sim ao modelo proposto por Canavilhas (2006) ao tratar da arquitetura da notícia na Web, a PD. Destacamos, entretanto, que, assim como o autor, não estamos sugerindo que o modelo da PI esteja sendo substituído ou invalidado no contexto da Web; nossos dados nos levam apenas a concordar com Canavilhas (2006) quando este afirma que em um ambiente hipertextual a PI tende a ficar restrita à estrutura interna de algumas células informativas. Sugerimos, dessa maneira, uma segunda consideração, que indica que a estrutura técnica padrão é alterada se observada através da (macro)estrutura da notícia on-line.

Cabe ressaltarmos que a limitação de caracteres por mensagens já impede que a organização interna dos tweets jornalísticos se dê através da PI ou represente a mera transposição do Lide tradicional. Fazendo uma analogia com o enunciado padrão, o tweet jornalístico poderia funcionar, em razão das características de concisão, como o Lide. Todavia, nossa observação do corpus demonstrou que o tweet jornalístico origina uma estrutura diferenciada centrada na apresentação de três elementos essenciais: "o quê?", "quem?" e "onde?". Assim, acreditamos que a limitação da ferramenta dá origem a uma estrutura hiperconcisa que denominamos de "microlide". Evidenciamos em nossa análise que a hiperconcisão exigida para a pretensa fluência dos enunciados jornalística no Twitter, estimula a apropriação por parte dos veículos/jornalistas da microssintaxe específica da ferramenta (LEMOS; SANTAELLA, 2010). Percebemos que a inserção dos elementos de microssintaxe (RT, @ e \#) na elaboração dos enunciados jornalísticos não indica apenas a assimilação de recursos técnicos, mas principalmente uma reformulação na forma de comunicar. Nossa terceira consideração, portanto, faz referência ao aparecimento do "microlide" como um novo formato que emerge dos tweets jornalísticos, funcionando como uma unidade-base, hiperconcisa, da (macro)estrutura da exploração noticiosa on-line e não como uma célula hierarquicamente mais relevante, como ocorre com o Lide do enunciado padrão.

Se trabalhamos com a ideia de que a linguagem jornalística padrão é caracterizada e permeada pela sociedade da escrita, fruto do século XIX, acreditamos, por fim, que o enunciado jornalístico no Twitter é caracterizado pela lógica da sociedade em rede. Assim, nossa segunda preocupação ao longo do trabalho foi demonstrar que as características tradicionais do enunciado jornalístico começam a ceder espaço para novos apontamentos que se voltam para as características 
de: hipertextualidade, hiperconcisão, interatividade, universalidade e colaboração. Tais características terminam permeando todos os enunciados construídos e veiculados através da ferramenta e tornam-se especificidades de seus conteúdos. A relação do Twitter com o jornalismo ainda é muito recente para que façamos previsões consistentes sobre o futuro dessa parceria. Ao certo, só podemos dizer que o Twitter está ganhando cada vez mais espaço como suporte de mídia social através do qual as notícias são construídas, apropriadas e ressignificadas por meio da interação entre informações e sujeitos diversos.

\section{NOTAS}

1 Tradução nossa para "What’s Happening?".

2 A Pirâmide Invertida é um modelo técnico de redação que visa à exposição dos elementos informativos em ordem decrescente de importância. O modelo ganhou especial destaque no jornalismo ocidental após a Segunda Guerra Mundial (1939-1945), mas sua origem está ligada ao século XIX e ao pensamento positivista.

3 O enunciado é entendido aqui como o resultado "observável" da ação do sujeito falante (BAKHTIN, 1995). Ao enunciado, portanto, se identifica o dito, como equiparação da língua em sua atualização através do ato de fala. Assim, o enunciado aparece como a instância de mediação que assegura a colocação em enunciado-discurso das virtualidades da língua.

4 Ao se referir ao "saber de narração" jornalística, Traquina (2008), deixa claro que o jornalismo possui uma forma especializada de contar suas histórias. Esse saber narrativo guia a formatação das notícias através de enunciados estabilizados. Assim, os saberes de narração podem ser traduzidos pelas técnicas (PI e Lide) que solidificam o formato da notícia e formatam o "jornalês".

5 A enunciação se identifica como a ação que promove o "dito", ou seja, o enunciado (GOMES, 2000). A enunciação é, portanto, de natureza accional e existe mostrando-se através do enunciado. Toda enunciação conta com a presença de, pelo menos dois sujeitos discursivos, o enunciador (aquele que fala) e o enunciatário (aquele para quem se fala).

6 Podemos definir o discurso referencial como o discurso da verdade, ou seja, aquele que busca apagar as marcas da mediação inevitável entre o fato real e sua construção enquanto enunciado ou elemento sígnico. 
7 Entendemos o termo discurso como o um conjunto de enunciados regulados numa mesma formação discursiva (FOUCAULT, 1973, p. 97). Segundo o autor, o discurso é "um conjunto de regras anônimas, históricas, sempre determinadas no tempo e no espaço que definiram em uma época dada, e para uma área social, econômica, geográfica ou lingüística dada, as condições da função enunciativa".

8 Os SRSs são espaços utilizados e destinados à expressão das redes sociais (conjunto entre atores e suas conexões) na Internet (RECUERO, 2009). De acordo com Boyd \& Ellison (2007), para que um sistema seja considerado um SRS, ele precisa permitir: a construção de uma representação do eu, através de perfil ou página pessoal; a interação através de comentários/ mensagens; e a exposição pública da rede social de cada ator.

9 Esclarecemos que Canavilhas (2006) não sugere a extinção ou supressão do modelo da PI, mas indica que a hierarquização representada pelo modelo fica, na Web, restrita à exploração interna de cada célula informativa. Ou seja, a notícia exposta em um jornal on-line pode ser estruturada através da PI, mas a macroestrutura hipertextual que a conecta a outras células informativas (como vídeos, tweets, arquivos etc.) estará sustentada pela PD.

10 Nos tweets, a presença expressa do link sugere uma espécie de "fonte intermediária" entre o enunciado e a realidade.

\section{REFERÊNCIAS}

BAKHTIN, Mikhail. Marxismo e Filosofia da Linguagem. São Paulo: Hucitec, 1995.

BOYD, Danah; ELLISON, Nicole. Social network sites: definition, history, and scholarship. In Journal of Computer-Mediated Communication. 2007. Disponível em: <http://jcmc.indiana.edu/vol13/issuel/boyd. ellison.html>. Acesso em: 28 set. 2008.

CANAVILHAS, João. Webjornalismo: da pirâmide invertida à pirâmide deitada. 2006. Disponível em: <http://www.bocc.ubi.pt/_esp/autor. php?codautor=602>. Acesso em: 17 jan. 2010.

CASTELLS, Manuel. A sociedade em rede. São Paulo: Paz e terra, 2010. (A era da informação: economia, sociedade e cultura, v.1)

CORREIA, João Carlos. O admirável Mundo das Notícias: Teorias e Métodos. Labcom, 2011.

FOUCAULT, Michel. A ordem do discurso.Ijuí: Fidene, 1973.

FRANCO, Guillermo. Bogotá, 2001. Comience cada página con las conclusiones. 2001. Disponível em:<http://www.univalle.edu.co/ 
publicos/documentos/como-escribir2.html>. Acesso em: 30 nov. 2010. GOMES, Mayra Rodrigues. Jornalismo e ciências da linguagem. São Paulo: Hacker, 2000.

LÉVY, Pierre. Cibercultura. São Paulo: Ed. 34, 1999.

MIELNICZUK, Luciana. A Pirâmide Invertida na época do webjornalismo. 2002. Disponível em: <http://galaxy.intercom.org. br:8180/dspace/handle/1904/18841>. Acesso em: 16 de março de 2011.

RAMOS, Tagil Oliveira. Twitter: chiclete \& camisinha. São Paulo: Novatec, 2010.

RECUERO, Raquel. Redes Sociais na Internet. Porto Alegre: Sulina, 2009.

SANTAELLA, Lúcia; LEMOS, Renata. Redes sociais digitais: a cognição conectiva do Twitter. São Paulo: Paulus, 2010.

SOUSA, Jorge Pedro. Elementos de Jornalismo Impresso. 2001. Disponível em: <www.bocc.ubi.pt/_esp/autor.php?codautor=13>. Acesso em: 16 mar. 2011.

TRAQUINA, Nelson. Porque as notícias são como são. Florianópolis: Insular, 2005. (Teorias do jornalismo, v. 1)

A tribo jornalística - uma comunidade interpretativa transnacional. Florianópolis: Insular, 2008. (Teorias do jornalismo, v. 2)

ZAGO, Gabriela. Jornalismo em microblogs: um estudo das apropriações jornalísticas do Twitter. 2008. Disponível em: <http:// pt.scribd.com/doc/5887184/O-Twitter-como-suporte-para-producao-edifusao-de-conteudos-jornalisticos>. Acesso em: 10 maio 2011.

\section{Mabel Teixeira possui graduação em Comunicação Social com} habilitação em Jornalismo pela Universidade Católica de Pelotas (2007). Mestre em Letras e doutoranda pelo Programa de Pós-Graduação em Letras (concentração em Linguística Aplicada) da Universidade Católica de Pelotas. Possui especial interesse pela pesquisa da linguagem jornalística e suas hibridizações nos novos ambientes midiáticos oriundos da Web. E-mail: mabel.ppg@gmail.com 